\title{
Improving Competences of Newly Qualified Professionals
}

\author{
Kim E. Tosolini
}

\begin{abstract}
Introduction: Very little research has been done on the transition of newly qualified professionals onto the working field. With present study the researcher wanted to investigate whether introducing newly qualified professionals to a specific theoretical model, can help improve their competence in the field of deafblindness. The study was specifically aimed at an intervention in applying the Real Space Blend Model. Method: The study used a qualitative design based on individual video-analyses and focus groups. Results: In two of the newly qualified professionals an increase in the number of gestures was seen. Such an increase was also found for one of the expert professionals. Two other expert professionals showed a little change in the overall number of gestures. From the thematic analysis, different themes came forward for each focus group. Conclusion and discussion: Newly qualified professionals seemed overall more confident after the intervention, expert professionals felt more aware about their identification of gestures in practice and found the model useful in practice to add on the Diagnostic Intervention Model. Some limitations of this study were the small amount of participants and that there were more experienced professionals than newly qualified professionals. More extensive research on the transition of newly qualified professionals is recommended.
\end{abstract}

\section{Keywords}

Competences, new professionals, communication, gestures, deafblindness. 


\section{Introduction}

When speaking about deafblindness, there is no general agreement about a unified definition. This is due to the discrepancies in different fields of science, which lead to inconsistent definitions of deafblindness, and to the great heterogeneity of the population (Ask Larsen \& Damen, 2014). During the Nordic Conference in 1986 the following consensus was found about deafblindness: it is a distinct disability that involves a combined vision and hearing impairment and it causes serious problems in three main areas: communication, orientation in the environment and access to information (Rødbroe \& Janssen, 2006). Congenital deafblindness (from here on: CDB) places severe limitations on the persons' access to communication and language because it occurs prior to the development of language (Dammeyer, 2012): this makes persons with $\mathrm{CDB}$ more reliant on the communication partners who can provide compensatory strategies to communicate (Bruce, 2005). To meet communication partners that are skilled in interacting with people with CDB using these compensatory strategies is very important for the development of persons with CDB (Rødbroe \& Janssen, 2006).

Developing the skills to interact with a person with CDB takes time and experience. Over the course of their careers, professionals change how they think, how they act in practice and how they interact with clients. Professionals use their experiences as the basis for making these changes (Daley, 1999). But newly qualified professionals often feel thrown in at the deep end when they start working (Whallett, 2017), and little empirical research has been performed on newly qualified professionals' transition into the workplace (Moriarty, Manthorpe, Stevens \& Hussein, 2011). Debates about the extent to which qualifying education prepares students to become effective practitioners in the field of all kinds of caregiving work, including that of $\mathrm{CDB}$, are not new. One consistent aspect of practice is the vulnerability experienced by those who are newly qualified, due to the differences between them and the experienced professionals. Research has found that policy documents provide over all little prescription on how support should be delivered during the transition to the workplace (Scholes, Petty, Mcintosh, Green \& Flegg, 2017), even though it can differ from country to country. Previous research has also shown that training alone cannot prepare students for a career in the supporting professions: time, experience and working with more expert professionals seem to be the only real way to learn competences in the field, with the first year in post-qualification practice likely to be a particularly important one (Jack \& Donnellan, 2010). A theoretical framework identified in the literature about the transition from novice to expert was given by Dreyfus and Dreyfus (1986), who summarized the five stages of skill acquisition as: 
novice, advanced beginner, competent, proficient and expert. Dreyfus and Dreyfus's five-stage model was later enhanced by including two further stages, pre-student and experienced, each at one end of the continuum (Fook, Ryan \& Hawkins, 2002). The authors suggested that newly qualified professionals in the field of caregiving were generally at the 'advanced beginner' stage and that their substantive knowledge (i.e. information about facts, concepts and relationships) tended to be better developed than their procedural knowledge (i.e. information about how to reason with substantive knowledge and how to make decisions).

Newly qualified workers express mixed views about their training, with most having enjoyed it or considered it useful, but conveying less satisfaction with how it had prepared them for the transition to the working field (Pithouse \& Scourfield, 2002). It is therefore important to investigate how this transition could be easier for newly qualified professionals. Present study wanted to investigate whether introducing newly qualified professionals to a specific theoretical model, can help improve their competence: specifically for the field of deafblindness.

The study was specifically aimed at a training in applying the Real Space Blend Model to improve competences in the interpretations of gestures of persons with CDB in professionals. The concept of interpretations of gestures in this study stands for: the meaning that the professionals give to a gesture or utterance when they see it. The model of Real Space Blends is primarily designed to grasp the structural dynamics of sign language (Souriau, 2015) and it is useful for its capacity to describe gestures and expressions. It is therefore a good example of a theoretical model involving the interpretations of gestures of persons with CDB. Also, it is a good addition to the Diagnostic Intervention Model (Janssen, Van Den Tillaart, Van Der Heijden, Van Duijnhoven \& Van Son, 2002), which is commonly used in the field of CDB in the Netherlands. The Real Space Blend Model is better suited for the present study because of its focus on the interpretation of gestures and their meaning, and specifically the relation between sign language gestures and natural gestures. The Diagnostic Intervention Model is a model that focuses on the interaction between persons with $\mathrm{CDB}$ and their communication partners, and aims to improve interaction aspects such as mutual attunement and sharing of emotions. In applying that model communication partners learn to recognize and attune to the behaviors and emotions of the persons with CDB (Janssen, et al., 2002; Janssen, Riksen-Walraven \& Van Dijk, 2003), while the aim of this study is that professional communication partners improve competences or skills in recognizing and interpreting the meaning of gestures and signs. Furthermore, while it takes quite some time and practice to apply the Diagnostic Intervention Model because it is a process model, the Real Space Blends Model is better suited to teach to newly qualified professionals because it is a theoretical model 
which can be immediately applied by communication partners in practice focused on meaning making.

The model of the Real Space Blends is particularly interesting for the interpretation of gestures of persons with deafblindness, because it provides a method to understand if and how the gestures carry meaning (Souriau, 2015). This can be a very difficult task, seen that persons with CDB usually communicate with gestures and movements which do not belong to a predefined symbolic system such as would happen in a more mainstream signed conversation.

The term Real Space Blends was introduced by Scott Liddell (2003) and is defined as a person's conceptualization of the immediate environment. It is a framework that is focused on the description of the process that takes place during a conversation. There is an activation of two mental spaces in the speaker's and listener's mind: a Narrative Space and a Real Space. This happens because sign language grammar cannot list all the ways in which signs are located and directed (Souriau, 2015). One needs more than just grammar to tell a story, and to understand another person one needs to combine those different mental spaces a person is referring to. With this model, Liddell suggests that signs and gestures are produced in a space that is not only the physical place where a conversation takes place (the Real Space), but also the mental space to which the utterances refer to (the Narrative Space). These two spaces then blend together: invisible elements of the Narrative Space are directly mapped onto visible elements of the Real Space. In other words, the Narrative Space elements (those elements that are not physically part of the local reality at that moment) are projected onto elements of the Real Space, and this process forms a new space from the blend between the two previous spaces. In simple terms: the combination of Real Space and Narrative Space leads to a Blended Space.

In short, it is possible to state that the process of combining different mental spaces is a universal process and it takes place between all humans when they try to communicate in every possible form. The Real Space Blends model helps understanding this process and is especially suited to analyze communication forms of persons with deafblindness. It could therefore be a useful tool to hand to newly qualified professionals to increase their competences and reduce the gap between them and expert professionals.

The main research question is formulated as follows: To what extent can a training in applying the Real Space Blend Model improve competences in interpreting gestures of persons with $\mathrm{CDB}$ in newly qualified professionals compared to expert professionals? The study will be focused on the following sub-questions: 
1. To what extent are there differences between newly qualified and expert professionals in the interpretation of gestures of persons with CDB before the intervention?

2. To what extent does expertise in interpreting the gestures increase after the intervention, for each group?

3. To what extent are the differences in the interpretation of gestures of persons with CDB between the two groups reduced after the intervention?

The assumption was that both, newly qualified and expert professionals, would benefit from the intervention due to the training and the performing of multiple videoanalyses, but that the impact of the intervention will be higher on newly qualified professionals.

This research could be socially relevant to the field of deafblindness and even of special education in general: it could lead to the suggestion that handing out the competence of a specific tool to novices may help them during the transition to the working field. There is over all very few literature that addresses the differences between newly qualified and expert professionals in the field of deafblindness. Therefore this study is also a good contribution to the scientific field of CDB.

\section{Method}

\section{Research design}

The study is a qualitative research that used individual video-analyses and focus groups. The hallmark of focus groups is the explicit use of group interaction to produce data (Flick, 2014). The discussions were recorded by the researcher, who also conducted the focus group. Using this method, the main question has been answered on an individual level to see individual differences between professionals and on a group level, to keep into account the fact that video-analysis in the field of deafblindness usually occurs in a group setting.

\section{Video-analysis.}

The professionals each individually performed two video-analyses of one videofragment: once before the intervention about Real Space Blends and once after. They were during both occasions asked to write down all the expressions and gestures that they thought could have a meaning. They were handed a format with a writing space for every 10 seconds of fragment. All participants saw the fragment twice in its entirety, and subsequently in smaller fragments of 10 seconds (each 10 second fragment was shown three times). 


\section{Focus groups.}

There have been focus groups with newly qualified professionals (one before and one after the intervention), with expert professionals (one before and one after the intervention) and one mixed focus group in the end, after the intervention. The discussions were video recorded by the researcher, who also acted as the moderator of the discussions. This was done by asking the participants open questions about the video analysis that they made, for example by asking if they could reflect on their process of recognizing gestures. The questions led the participants to discuss what the researcher needed, but the participants were let free in what they wanted to say and whether they would like to respond to each other's comments or not.

\section{Setting.}

The various professionals participating in the study were selected from the team working at Talant in Stiens (NL)(for informed consent see ethical considerations). This is an institution that provides care for people that need assisted living, such as people with deafblindness. An educational psychologist is responsible for the clients with deafblindness and for the supervision of the professional support workers. The researcher executed an internship in special needs education under the supervision of this educational psychologist. The institution and that psychologist have been collaborating for a long time with Professor Janssen of the University of Groningen also on research with the Diagnostic Intervention Model. The psychologist indicated that the present research on improving competences or skills in interpreting gestures and signs of newly qualified and expert professionals would be interesting, not only for supporting the new ones but also to motivate the experienced professionals. The recruitment of participants was performed by the researcher, under the responsibility of the educational psychologist. The study took place from January until June, with data collection between March and April. The focus group discussions were held with intervals of circa 10 days.

\section{Participants.}

The various professionals participating in the focus groups were selected by purposive sampling (Flick, 2014). It was a prerequisite that all participants did not have knowledge of the Real Space Blend model, so that the amount of experience was the only difference between the professionals.

The selection criterion to be an expert professional in this research was: a professional that has been working in the field of deafblindness for at least 5 years. The newly qualified professionals were those that had been working in the field of deafblindness for less than a year and had no previous experience with persons with 
deafblindness and neither with e.g. deaf or blind persons. As the field of deafblindness is a rather small one, professionals working in it are often very happy to participate in studies, workshops and in-service training to improve their knowledge. This was also the case with the participants of this study. Furthermore, as the participants participated on a voluntary basis, the risk of drop-outs was reduced to its minimum.

There was a total of three newly qualified professionals participating in the focus group. All three of them were working as caregivers of people with deafblindness since a couple of months and thus met the inclusion criteria. All three of them were women, with an official caregiver certification from the Dutch Intermediate Vocational Education (MBO). They had varying ages between 20 and 55. One of them was especially interested in the study due to the fact that she just very recently transitioned to the field of $\mathrm{CDB}$ and was interested in learning new skills. Also the other two newly qualified professionals participated to learn new skills and were interested in the fact that it could give them more confidence. All participants in this group never had performed a video analysis.

There was a total of four expert professionals participating in the focus group. All participants had been working for more than five years with people with deafblindness, two of them even for more than ten years. They too all met the inclusion criteria. There were three women and one man, of varying ages between 20 and 45 years old. They had been schooled by the Dutch Intermediate Vocational Education (MBO). All participants were interested in the study to keep up to date about new models, because by learning new things their work has constant new challenges that keep it interesting. Also, as they were very passionate about their jobs, they want to provide the best care for the people they work with, and this includes never to stop learning new things. All participants in this group were skilled in performing video analyses and followed multiple trainings. There were no drop-outs during the period of research.

The researcher had different tasks during the research project: she gave the training to the focus groups, was the moderator of all focus groups and analyzed the results. Due to the fact that she is a newly qualified professional herself, taking on different roles could lead to a certain bias. But this does not rule out the fact that in qualitative research it is important that the gathering of data is an interactive process with the participants (Flick, 2014). By the different roles that the researcher took on, she could gain information on a broader basis.

\section{Research procedure and data collection}

(a) First measurement: the professionals in each group individually performed at the same moment a video-analysis of video $\mathrm{X}$. They were asked to make 
individually a list of the expressions that they identified as having potential meaning. Then the researcher asked the participants to reflect on the way they identified expressions. This marked the beginning of the focus group discussion and the participants started discussing with each other how they identified expressions and what they thought about their process of identifying them. When the discussion stopped, the researcher asked new questions such as "what did you find difficult or easy while identifying gestures in the fragment?". With new questions, the discussion began again. Throughout the focus group the questions were leading the conversation to certain subjects, but the participants were left free to discuss open with each other.

(b) Intervention: the researcher introduced the professionals to the Real Space Blend model in the form of a lecture and a practicum with the model in which they exercised video analyses on multiple video fragments. All professionals were present during the same intervention and had therefore access to the same information. During the lecture the professionals gained theoretical knowledge about the Real Space Blends, through listening to a presentation given by the researcher. This presentation contained an explanation of the relevant terms of the model, such as Narrative Space, Real Space, Blended Space, mappings. In addition, relevant literature was given to them, such as Liddell (2003). Afterwards, the researcher practiced together with the participants the analysis of a video sequence $Y$ shown to them. The researcher gave some examples, with which they could practice together and on their own, for as long as needed and with the possibility to ask questions. Video $\mathrm{Y}$ was different from the fragment shown in the first measurement.

(c) Second measurement: the professionals in each group individually performed at the same moment a second video-analysis of the same video $X$ and had the same tasks as in the first measurement (a). Then when the researcher asked again about their thought on the identification of gestures, a second discussion started. The participants were again left free in their discussion, with the exception of some guiding questions. This time, questions such as "did you notice any differences compared to the first analysis?" were asked, to have them make a comparison between the first and second measurement.

(d) Final discussion: the two groups came together forming one focus group. Here, a discussion was held about what the professionals thought differences between them would be and how this impacted the way they identified gestures. Some leading questions were given by the researcher, such as "What were the differences between the first and second analysis?". The newly qualified professionals and the expert professionals were encouraged to answer the 
questions and respond to one another to discover the differences between the two groups. The participants were free to tell their opinions and discuss it with each other.

There thus were different sources for the data: the individual lists of expressions with the number of expressions that the professionals have identified during the first and second measurement were used to look at individual differences; the video recorded discussions between professionals both in the separated focus groups and the final mixed focus group with all the professionals was used to look at the group differences.

\section{Data analysis}

\section{Individual data.}

The lists of expressions was analyzed quantitatively by comparing them with each other based on the number of expressions identified. The researcher looked for differences in the number of identified expressions, such as whether participants experienced a process of gradual change in the number or not. The researcher looked for every participant at the mean number of expressions identified per 10 seconds and at the overall identified expressions for the whole fragment. This was done to see both the possible change in the mean numbers as well as the precise numbers, so that a complete overview of the data would be given.

\section{Group data.}

The recorded discussions of the focus groups were analyzed through a qualitative thematic coding analysis (Robson, 2011). During this process the recording was transcribed and all parts of the data were coded. Coding was followed by grouping the initial codes into a smaller number of themes and subthemes (Flick, 2014). For a higher reliability (Robson, 2011), the researcher asked someone that was independent from the research to perform the same coding. By doing this, two sets of codes were available. To check the validity of data, the researcher used a consensus check by communicative validation (Flick, 2014). The two coders separately coded the data but then looked at it together to see if there were any important differences. This way, especially the evaluative validity, which refers to the adequacy of the framework used for categorizing a statement in a specific category, was kept high.

\section{Ethical considerations}

The study was conducted at an institution for people with different needs and under the supervision of an expert educational psychologist. The content supervision was done under supervision of the university. The study was not likely to affect the 
emotional well-being of participants nor did it violate the privacy of any participants as the data was dealt with anonymously. All participants participated in the study on a voluntary basis and gave their explicit consent which was written down. All participants were kept informed during the study. The participants had, throughout the whole study, the right to stop or object against their data being used.

This study is considered an important contribution to the scientific field. It is very important for newly qualified professionals to feel as confident as possible because the people with CDB they work with are totally depending on their communication partners. Furthermore, a great amount of their job is to have exchanges with the experienced partners about what they see in their contacts with the people with CDB. Professionals always work in a team, and it is therefore of importance to have confident newly qualified professionals and good relations with the expert professionals to keep challenging oneself to become a better professional.

\section{Results}

\section{Results of individual video-analyses in the newly qualified professionals' group}

In table 1, an overview is given of the numbers of expressions found by the newly qualified participants. Both the mean number of expressions for the 10 second fragments and the overall expressions identified in the whole fragment are given.

As can be seen in Table 1, for two of the three participants a considerable change in identified expressions took place after the lecture. This can be seen both in the mean number of expressions and in the overall number of expressions identified. For one participant the number of expressions remained almost the same, with no change. 
Table 1.

Numbers of identified expressions in newly qualified professionals

\begin{tabular}{lllll}
\hline Participants & $\begin{array}{l}\text { Mean number of } \\
\text { identified } \\
\text { expressions } \\
\text { before the lecture } \\
\text { (Per } 10\end{array}$ & $\begin{array}{l}\text { Mean number of } \\
\text { identified } \\
\text { expressions after } \\
\text { the lecture (Per } \\
10 \text { seconds) }\end{array}$ & $\begin{array}{l}\text { Overall } \\
\text { identified } \\
\text { expressions } \\
\text { before the } \\
\text { lecture (for the } \\
\text { whole fragment) }\end{array}$ & $\begin{array}{l}\text { Overall identified } \\
\text { expressions after } \\
\text { the lecture (for } \\
\text { the whole } \\
\text { fragment) }\end{array}$ \\
\hline 1 & 3 & 32 & 51 \\
\hline 3 & 5 & 4 & 23 & 31
\end{tabular}

\section{Results of individual video-analyses in the expert professionals' group}

In table 2, an overview is given of the numbers of expressions found by the expert participants. Both the mean number of expressions for the 10 second fragments and the overall expressions identified in the whole fragment are given.

As can be seen in Table 2, one of the participants had a considerable change in the number of identified expressions. Two of the participants had no change but identified an equal amount of expressions before and after the lecture when looking at the mean expressions, but had a little change in the overall number of expressions. One participant identified less expressions after the intervention than before. 
Table 2.

Numbers of identified expressions in expert professionals

\begin{tabular}{|c|c|c|c|c|}
\hline Participants & $\begin{array}{l}\text { Mean number of } \\
\text { identified } \\
\text { expressions before } \\
\text { the lecture (Per } 10 \\
\text { seconds) }\end{array}$ & $\begin{array}{l}\text { Mean number of } \\
\text { identified } \\
\text { expressions } \\
\text { after } \\
\text { the lecture (Per } \\
10 \text { seconds) }\end{array}$ & $\begin{array}{l}\text { Overall identified } \\
\text { expressions before the } \\
\text { lecture (for the whole } \\
\text { fragment) }\end{array}$ & $\begin{array}{l}\text { Overall } \\
\text { identified } \\
\text { expressions } \\
\text { after the lecture } \\
\text { (for the whole } \\
\text { fragment) }\end{array}$ \\
\hline
\end{tabular}

\begin{tabular}{lllll}
\hline 1 & 4 & 4 & 41 & 43 \\
\hline 2 & $\mathbf{6}$ & $\mathbf{7}$ & $\mathbf{6 1}$ & $\mathbf{7 3}$ \\
\hline 3 & 5 & 5 & 49 & 50 \\
\hline 4 & 3 & 2 & 32 & 24 \\
\hline
\end{tabular}

Results of thematic coding of the newly qualified professionals' group before the intervention

Two main themes were found during the focus group of newly qualified professionals before the lecture about Real Space Ble nds: (1) Subjectiveness and (2) Difficulties. These themes repeatedly came forward when talking about the interpretation of the fragment. The participants verbally expressed feeling too subjective about what was happening in the fragment and expressed difficulties in putting into words what they were seeing.

(1) Subjectiveness

1. Subtheme: Own interpretations. All participants talked about giving own interpretations to what was happening in the fragments really quickly, and wondered if this was a good thing to do or not. They told the researcher they were insecure about the meanings they were giving:

2. Subtheme: Focus of attention. The participants caught themselves looking with more

attention to the little boy than to the mother in the fragment. One participant expressed this out loud and the other participants all agreed they were doing the same thing. 
(2) Difficulties

1. Subtheme: Putting gestures into words. Two participants told the researcher they found it quite difficult to express themselves when trying to write down the gestures. They were aware that many things were happening in the fragment, but they were very hesitant when writing it down. They expressed this concern multiple times.

2. Subtheme: Identifying communication. Two of the participants said they were doubting about what could be seen as communication. They wondered if everything they saw could be categorized as communication. When speaking about this subtheme, they changed their point of view multiple times while discussing it, showing to be hesitant, as can be seen in the quotes of participant 1 :

$\mathrm{R} 1:$ "But is this [referring to a gesture seen in the fragment] communication? Or just a movement? I think not everything is communication but sometimes you see gestures that are purely some kind of movement, so I wouldn't write that down as gesture"

R2: “But maybe we don't see it as communication but it is communication for them. Like, maybe he is trying to communicate but we don't see it the right way."

R1: "Hmm... Yes, I think you're right. Maybe I have to think more from their [persons in the fragment] perspective then. Like for them probably everything has a meaning, even if it doesn't have one for us."

\section{Results of thematic coding of the newly qualified professionals' group after the intervention}

After the lecture about the Real Space Blend, new themes came forward in the group. The three most important ones were (1) Objectiveness, (2) Awareness and (3) Meaning of gestures. The participants felt like they now had a more specific way of looking at the fragment, helping them in being more aware about the overall communication that was happening between the two, taking into account not only what was happening, but also what they were communicating about and how they were expressing things.

\section{(1) Objectiveness}

1. Subtheme: Ways of looking. All three participants said that by looking at the fragments through a clear theoretical model their way of looking changed. They said 
they felt like having a clearer purpose while looking and were therefore less hesitant about what they would write down.

R2: "It struck me that you look in a different way now. While in the first analysis I was very focused on myself, on what I was writing and if it was right, I now think I was much more concentrated on what I was actually seeing. It's like I was seeing the bigger picture now, about the communication happening."

\section{(2) Awareness}

1. Subtheme: Increasing complexity. Two of the participants noticed that the more they were looking at the fragments, the more they were seeing. When pointed to the fact that they expressed this before the lecture too, and when asked if there was a difference, they agreed on the following: while before the lecture they found this fact confronting, because they did not know how to interpret every new gesture seen, they now felt like they could handle it better. Instead of finding it confronting, they now found it challenging. The third participant agreed on this.

R3: "It's curious to see that you suddenly see many more things. Every time we look there are more expressions of which I now think "oh this could be something, it's a blended space and it stands for this!" but then you go further and even in that same gesture you start seeing other, smaller ones, and it could go on and on!".

2. Subtheme: Thinking process. All participants agreed about being more aware about their own thinking process. They were positive about the knowledge they now had acquired and felt like processing what they were seeing through a clear framework was helping them writing down things in more specific terms instead of wondering if they were doing it wrong.

3. Subtheme: Confidence. As a consequence of the previous subtheme, all participants told the researcher they felt more confident while performing the second video-analysis. They found working with a specific framework had increased their feelings of confidence because they had specific terms that they could use in the analysis and this made them less afraid to make mistakes. 
(3) Meaning of gestures

1. Subtheme: Overall communication. All participants agreed that they looked at the communication taking place in the fragment in a different manner after the lecture. While beforehand they were very focused on themselves and if they were seeing the right things, they were now much more focused on the communication taking place in the fragment.

R2: "It's like I was seeing the bigger picture now, about the communication happening. I was looking much more at the whole communication, at what every little thing could stand for, at the beautiful interaction between the two. And I mean, it's not that I did not see it the first time, but now I was very focused on what everything could stand for. In the first analysis it was mostly looking at what they were doing and what the general meaning could be. Now it's much more attention to the little things, and to smaller meanings in the overall story".

2. Subtheme: Translation to the working floor. One participant expressed that she was quite fascinated with the concept of Blended Spaces. The other participants agreed on the fact that it was a model that really made them think. They related the model to their daily jobs, and how they could be more aware of the gestures made by the persons with CDB they were working with.

R1: "It really intrigues me [the Blended Space]. Because if you think of it, it happens a lot. Like maybe our clients are trying to tell us something about what happened to them, but we don't understand it because we see it as just a movement. When instead, it stands for something."

R3: "But it is also quite difficult. Because if you do not know what he or she means, you can't understand the gesture and you don't know that it stands for something".

R2: "Yes, because it's also true that our clients usually use gestures that maybe have meaning for themselves, but would not be logical to us.

R1: "Yes, so to know what they have experienced is important. This is sometimes very difficult to know. But maybe now we can be more alert in looking if the gestures they make stand for something that we don't see."

\section{Results of thematic coding of the expert professionals' group before the intervention}

In the group of expert professionals, two themes came forward during the focus group discussions: (1) Theoretical frameworks and (2) Specificity of meaning giving. All participants analyzed the fragment in terms of interaction categories from the 
Diagnostic Intervention Model (Janssen, Van Den Tillaart, Van Der Heijden, Van Duijnhoven, Van Son, 2002). This is the method they are thought to work with at their institution. Half of them looked for narratives in the fragment. Furthermore, they expressed some doubt about the specificity with which they wanted to describe gestures and meaning.

\section{(1)Theoretical frameworks}

1. Subtheme: The Diagnostic Intervention Model. All participants analysed the fragments especially in terms of turn-taking and initiatives (some terms from the Diagnostic Intervention Model). This really was the focus of the analysis in all four of them. When asked why they chose to analyse it that way, they all agreed it was their usual manner of interpreting a video.

R4: "It's the Contact Method [the Diagnostic Intervention Model]. We always use it when analysing a fragment because we have been taught that way. And it is really useful because you can think about who initiates the interaction and who is "speaking" in that moment. Which I think are very important things to know, because in that way you can see all the good aspects of the interaction."

2. Subtheme: Narratives. What also came forward during the focus group, was th t $t$ two out of four of the expert participants also focused on the narratives they could find in the fragment. They often used terms such as "introduction/building up" and "climax".

R2: "When you see him [boy in the fragment] and her [woman in the fragment] interacting at that point, you really see him smiling even before the climbing and whooshing activity begins. He has some anticipated pleasure while the woman builds the tension up to the climax".

\section{(2) Specificity of meaning giving}

1. Subtheme: Abstraction. Three out of four participants agreed that they were hesitant when writing down the gestures and meanings because they were often doubtful about whether to look for an overall, general meaning of what was happening or to write down every little specific gesture. When told that there are no wrong answers and when asked which of the two they had then chosen, the three reported having opted for the more general meaning, e.g. the narratives or the turns and initiatives. When asked why they chose to focus on that, they agreed on the fact that it was probably because they were used to do so. 
The fourth participant had a slightly different opinion than the rest:

R1: "I think that it's difficult to make a clear distinction between general and specific meanings, if you analyse something from the point of view of initiatives and turns you're still looking at the small gestures right? You have to integrate everything you see."

This led to an interesting discussion, leading to the conclusion that there is no good or wrong way of analyzing a fragment: they actually were looking at a lot of things at the same time. Still, they expressed they found it difficult to decide what to write down as gesture and what not.

\section{Results of thematic coding of the expert professionals' group after the intervention}

In the focus group of expert professionals after the lecture, the themes that came forward were: (1) Difficulties, (2) Meaning of gestures and (3) Interest in the Real Space Blend model. The expert professionals had somewhat more difficulties in grasping the model of the Real Space Blend and at times expressed some frustration about this. Still, the model really made them think about the meaning of gestures of the persons with CDB they are working with, and they said to be very interested in Liddell's (2003) research.

\section{(1) Difficulties}

1. Subtheme: Terms of the model. Two of the participants talked about having had some difficulties with the terminology of the model. They did not understand the difference between the Narrative and Blended Spaces. They were given multiple explanations, examples and all the time they needed to ask questions. After a while three of the four participants had grasped the model and could give many examples showing they had understood it. One participant kept having difficulties.

2. Subtheme: Putting the model in use. At the time of the second focus group, they all stated that they understood the model. After performing the second analysis, they discussed about how it's different to learn new theories and then putting them into practice during the video analysis. Two of the participants felt like they were looking at the gestures in a different way than before, but they did not really know how to express in what way it was different.

R3: "I think I'm thinking more about what a certain thing or gesture stands for now. But I find it hard to describe how I'm using the model. For example, I can recognize a Blended Space if I think consciously about it. But I think I'm doing it more implicitly than explicitly while watching the fragment. I still think more in terms of interaction categories most of the time." 
(2) Meaning of gestures

1. Subtheme: Translation to the work floor. During the discussion, the professionals often related the model to their own situations on the working floor. They discussed the fact that even though they work with people who can barely communicate due to their $\mathrm{CDB}$ in combination with profound intellectual disability and physical disability, it is still possible to pick up very small signals. These signals could stand for something important to the person, and if the professionals used the model in practice they could consciously think about e.g. what a signal could refer to.

R2: "If you for example think of J. [deafblind woman at the institution], I often have the impression that she is trying to communicate something. But you know, when we're busy I don't always have the time to sit with her and try to figure out what it is... but we really should do this. I mean, of course we try to figure out what she is trying to say, but not in depth like we are doing with the video-analysis and model right now. If we would do it in practice, we would probably find out a lot of things that we usually miss".

2. Subtheme: Awareness. All participants agreed on the fact that by giving gestures more attention through a specific framework during the video analysis, they found themselves to be more aware of how many little gestures can actually be missed. In turn, being aware of this would lead to them paying more attention to the meaning of gestures on the working floor, they stated.

\section{(3) Interest in the real Space Blend model}

1. Subtheme: Understanding of the importance of the model. One participant was particularly interested in the model and Liddell's research. During the focus group she stated more than once that she really understood why someone would want to do research about gestures and their meaning.

R1: "I really can imagine that someone would investigate this [gestures]. Because it is so important that we know as much as we can about it, we all should be much more sensitive to every little detail. And to have theoretical research is always useful, it helps you think more clearly because you can relate what you see to theory that you studied."

All participants then agreed with her, saying that in the working field it is always very important to keep up to date on new theoretical frameworks and research. They reported feeling more self-assured when knowing they had been keeping up with the theory. 


\section{Results of thematic coding of the mixed focus group after the intervention}

The last focus group was held with all expert and newly qualified professionals together, so that they could discuss about what similarities and differences were seen between the groups.

\section{(1) Similarities}

1. Subtheme: relating theory to the working field. During the discussions both newly qualified and expert professionals related the newly acquired knowledge to their own working floor. At some point they all discussed about how theoretical frameworks can help them with interpreting gestures of the persons with CDB they work with.

R2expert: "If you for example think of J. [deafblind woman at the institution], I often have the impression that she is trying to communicate something. [...] If we would do it in practice, [analyzing gestures] we would probably find out a lot of things that we usually miss".

R3newlyqualified: "[...] we could do this with our clients too. It's easier to do it through a videoanalysis of course, but it is important to try to do this on the working field too, while we work. So that you can at least consciously think about all the gestures that you see, even if the meaning is sometimes very difficult with the people we work with. It's a first step".

2. Subtheme: awareness. Both the newly qualified and the expert professionals found themselves being more aware about the possible meaning of gestures of the persons they work with. They all agreed that they were now more consciously aware of the importance of every little gesture and told the researcher that they were thinking more about what everything could mean.

R1newlyqualified: "It is really interesting because now I often find myself thinking about the possible meaning of a gesture in much more detail. Instead of only looking for the usual gestures that we recognize, I now look at all the gestures I see and start thinking about whether they could stand for something."

R3expert: "I think we are probably more aware now of all the things that can carry a possible meaning. That's why it is important to keep going to trainings."

\section{(2) Differences}

1. Subtheme: experience with video-analysis. The expert professionals had had multiple trainings in how to perform a video analysis, while the newly qualified 
professionals had never done a video analysis before. The participants mentioned this difference when speaking about how they wrote the gestures and meanings down. The main difference they talked about was the fact that the expert professionals had a very clear method of analyzing a video through the interaction categories of the Diagnostic Intervention Model. What struck them was that none of the newly qualified professionals had used these terms in their analysis, even though they too did get a training in the Diagnostic Intervention Model.

R4expert: "I think we all did it this way because it's what we are used. Maybe you three [the newly qualified professionals] know these terms too, but haven't used them enough to consciously use them in the analysis.

2. Subtheme: learning new theory. One big difference was that half of the expert professionals still found it a difficult model to understand, while all the newly qualified professionals really seemed to grasp it. The expert professionals that had difficulty with it stated that it was not specifically due to this model, but that they always had difficulties with new theory.

\footnotetext{
R4expert: "Maybe if you can send me some of the articles, I will understand it better in the future. I always just need more time with these things, that's it."

Rlnewlyqualified: “I think maybe for us it was even more interesting because we don't know many theoretical frameworks yet. They all have had so many lectures about so many models. I get why they could be confused sometimes. But we have not had many yet, so maybe that helps too."
}

The participants then agreed that for the expert professionals, it is much simpler to stick to very well-known frameworks than to new ones, mostly out of habit. Setting these frameworks aside to use new ones instead is then more difficult. Because the newly qualified professionals just started working, they probably have developed less habits, making it easier to integrate new knowledge. Still, it was very important for the expert professionals to underline the fact that this did not mean that they would not benefit from new theories.

\section{Results on the consensus coding}

Both the researcher and a second, independent coder performed a thematic analysis of the focus groups. They used the same method to make codes, grouping small codes such as "Narratives" together to form bigger themes as "Theoretical 
Frameworks". Then the two coders had a discussion together, to discuss whether the codes had major differences or not. Seen that the codes were quite similar, it was decided that the codes were sufficiently reliable. The researcher used both sets of codes in the results and conclusion, using the themes that were pointed out by both coders in the same way. This way, only the most reliable codes have been used. For example, both coders gave the code "Video-analysis experience", or "Confidence". Therefore, these codes were found reliable. Some codes were not identical, but quite similar, such as "translation to the working floor" and "put in practice". Here, the coders would discuss which code would be better suited for the statement and came to an agreement. Some codes were pointed out by just one coder. These codes have not been used, as they were found too subjective.

\section{Conclusion and discussion}

This research investigated how to reduce the gap between expert and newly qualified professionals when the latter make the transition to the working field. The study was aimed at improving the competences of these two group of professionals in interpreting gestures of persons with $\mathrm{CDB}$ by an intervention in applying the Real Space Blend Model. It can be stated that the intervention indeed improved competences in interpreting gestures of persons with CDB in newly qualified professionals. The extent to which this happened turned out to be more complicated. Both groups, newly qualified and expert professionals, benefited to some extent from the intervention, with the newly qualified professionals having a more considerable gradual change, but the two groups experienced different outcomes after the intervention. The newly qualified professionals indicated that they felt more confident and the expert professionals expressed that they felt more aware of the gestures but they expressed also to have some difficulties with grasping the model of Real Space Blends.

When looking at the first sub question, regarding the differences between the groups before intervention, the findings showed that expert professionals identified considerably more gestures than newly qualified, thanks to the use of the interaction categories of the Diagnostic Intervention Model. They had a clearer framework with which to look at the fragment. What came forward in the thematic analysis was that newly qualified professionals were overall more hesitant and expressed more difficulties while experts used specific terms and were more confident about their skills. Still, they also expressed hesitation about how specific or not the gestures they had seen had to be written down. 
With regard to the second sub question, data showed that both groups demonstrated an increase in the number of identified gestures after intervention. In newly qualified professionals it was a larger difference: two out of three participants identified more gestures. In the expert group only one participant showed a considerable increase while two participants showed a very small increase and even one participant showed a decrease in the number of identified gestures. This can be seen as a sign of realism of the data, since learning processes are never completely linear, but often show fluctuations (Leman, Bremmer, Parke, Gauvain, 2012). Based on the thematic analysis the researcher found that both groups experienced to be more aware about the possible meaning of gestures. Furthermore, the newly qualified professionals sounded as having more confidence after the intervention, because they felt like they had acquired a specific piece of knowledge that they could use. However the expert professionals expressed to have more difficulties after the intervention.

Regarding the third research question, when looking at the number of gestures, the gap between newly qualified and expert professionals doesn't seem to be relevantly diminished, since both groups benefited in some way from the lecture. Based on the thematic analysis some remarkable aspects came forward: newly qualified professionals felt more confident after the intervention, expressing they now had a clear model that they could use, while expert professionals expressed to have experienced more difficulties after the intervention than before. The latter group especially had difficulties in understanding the model.

In conclusion, it can be stated that all professionals benefited in some way from the intervention in applying the Real Space Blend Model, but a variety in outcomes was seen in how the different professionals benefited from the intervention and in the amount of benefits they got from it.

The participants reactions on the study were positive, and they were interested in receiving additional literature. A constructive discussion about the findings took place, where all participants expressed being very passionate about their work and how willing they were to always improve themselves to help the people with CDB they work with as best as they can. Some of them stated that this was also the reason why they wanted to participate in the study: willingness to learn something new, in the hope that they could provide even better care. Motives to participate were quite similar, all caregivers wanted to better themselves to be able to perform better on the working floor. A difference in motivation can be seen between the two groups though: expert professionals wanted to broaden their knowledge but also wanted to have something new to use on the working floor, to get renewed motivation while working, while newly qualified professionals mostly wanted to learn more to feel more confident to do their job well. Positive reactions were given about the different focus groups. All participant 
expressed finding it interesting, and the newly qualified professionals were quite happy to have had some exercise with analyzing video fragments. What came forward was that the newly qualified professionals were excited about having new knowledge that they could share with other colleagues. They felt like they had learned to use a tool through which they could easily communicate about gestures with more expert professionals, because they could use specific terms. Expert professionals on the other hand found it quite interesting that even though in practice they kept using the Diagnostic Intervention Model, they often thought about the Real Space Blend when seeing small gestures. They told the researcher that they felt like having learned a new model got them to be more alert to those smaller gestures. All professionals were satisfied with what they had learned, and repeatedly confirmed that they would never stop learning new things because working with people with CDB is their passion.

Overall, the results seem promising, and were found reliable enough, based on the communicative evaluation, to make this conclusion, thanks to the different sorts of efforts that were made to maintain as high a reliability as possible: different coders, using the exact same coding method, and a consensus check between the coders. With this consensus check, the decision was made that the codes were similar enough to be reliable and it was also decided to only use the codes that were used by both coders. This way, only the most reliable set of codes have been used.

Still, more extensive research is needed due to some limitations of this study. Firstly, the number of participants was quite small, due to the limited available resources and time. For future research it would be recommended to set up a research with more participants, so that the reliability of the results would be higher (Flick, 2014). On the positive side, having small focus groups allowed the researcher to have long, extensive conversations with the participants which led to very useful data. Secondly, even though every effort was made to minimize the differences between the group of newly qualified and expert professionals so that years of experience would be the only difference, it was impossible to account for the fact that the newly qualified professionals had never performed a video-analysis before, while the expert professionals had extensive experience with this. We cannot know with certainty the extent to which this affects the results of the research. It is recommended for further research to find a method better suited to measure differences between the groups, so that more differences can be accounted for. Furthermore, the motivation and readiness of each participant to learn the new model would have been useful to measure before the training started as it can predict commitment to learning the new knowledge and thus the learning outcomes. This could have perhaps explained why expert professionals had more difficulties with the model, because learning often varies based on e.g. motivation and needs of the individuals. A third limitation is that there were 
more participants in the expert professionals group than in the newly qualified professionals group. This difference was due to the simple fact that there were far more expert professionals working in the field than newly qualified ones. It would be recommended in the future to have to equally large groups, as to have an equal amount of data. Furthermore, it is recommended in future research to find a method better suited to analyze the number of gestures seen by the professionals: having to write them down was seen by the participants as difficult, probably because usually a videoanalysis is performed by talking without writing it down. This is what the professionals are used to and letting them write down the gestures may have caused some difficulties during the performing of the video-analysis. Methodologically, it is recommended to look for alternative methods, for example interviews with the participants, so that the method differs less from how a video-analysis happens in real life, leading to less difficulties for the participants. Lastly, while it was considered a strength during the collection of data, the fact that the researcher had multiple roles in the study had inseparably also some negative aspects. As she was an intern herself, she could unconsciously have had a bias for the newly qualified professionals, being one herself and did not oversee all relevant aspects of the study which required more experience not only as a researcher but also as a clinical professional.

Despite the limitations, interesting outcomes were found during this research. A significant increase in confidence was found in the newly qualified professionals. This finding is supported by a study (Orpen, 1999) which showed that taking part in formal training is associated with newly qualified employees feeling more confident in their ability to perform their jobs effectively. Even though we cannot prove that this reduces the gap between newly qualified and expert professionals, it can certainly be seen as a positive outcome, because previous research suggested a positive link between confidence and reduced anxiety levels (De Clercq, Ul Haq, Azeem, 2017) The more confident employees were about their own abilities, the less likely they felt overburdened by fears about their functioning on the job. Thus, lower anxiety, due to higher confidence, enabled employees to focus on the successful execution of their work tasks instead of being distracted by worries about their work (De Clercq, Ul Haq, Azeem, 2017). The researcher felt positive about this outcome,that could be seen as a first step towards a better transition to the working field for newly qualified professionals.

In the expert professional group something peculiar struck the researcher. It was remarkable that these expert professionals had quite more difficulties understanding the model than the other group. Even though they mentioned multiple times that it helped them being more aware about the gestures of people with CDB because they could look at them from a new, different angle, they also expressed their frustration 
about not grasping the model. It seemed that in this group, in contrast to the group of newly qualified professionals, teaching a new model is not simply adding a new piece of knowledge that they could just use, but it is changing their whole outlook on things because they try to fit new knowledge into earlier established sets of knowledge. This characteristic is in agreement with previous research, which confirmed that our ability to understand and remember new information critically depends upon what we already know and how our knowledge is organized (Clifton \& Slowiaczek, 1981).

Some important implications for practice could be formulated, based on this study. It is useful for newly qualified professionals to have a training in a specific theoretical model which helps them in feeling more secure about their abilities on the working floor. Expert professionals also benefit from new insights and are open to learning new skills, but benefit in different ways. In practice, we should keep in mind these differences and adapt our training programs to the ones following it: newly qualified professionals and expert professionals have different needs. As these differences could come from the professionals' willingness to learn new knowledge, it is recommended to gain more insights about this for a successful application of the Real Space Blend model in future practice. Different motivations lead to different outcomes and it is therefore important to have a good representation of the starting motivations and goals of professionals.

This study proved to be applicable in the deafblind field. More extensive research is of importance, not only in the deafblind field, but also in special needs education in general, to get better insights in this phenomenon. It is recommended to formulate more concrete starting points for practice, based on further research, to support the young, newly qualified professionals in making the transition to the working field as best as possible, so they can become satisfied and confident educational professionals.

\section{References}

Aelterman, A., Engels, N., Van Petegem, K., Verhaeghe, J.P. (2007). The Well-Being of Teachers in Flanders: The Importance of a Supportive School Culture. Educational Studies, 33(3), 285-297.

Ask Larsen, F., Damen, S. (2014). Definitions of deafblindness and congenital deafblindness. Research in Developmental Disabilities, 35, 2568-2576.

Bruce, S. (2005). The impact of congenital deafblindness on the struggle to symbolism. International Journal of Disability, Development and Education, 52(3), 233-251.

Clifton, C., Slowiaczek, M.L., (1981). Integrating new information with old knowledge. Memory \& Cognition, 9(2), 142-148. 
Daley, B., J. (1999). Novice to expert: an exploration of how professionals learn. Adult Education Quarterly, 49(4), 133-147.

Dammeyer, J. (2012). Identification of congenital deafblindness. The British Journal of Visual Impairment, 30(2), 101-107.

De Clercq, D., Ul Haq, I., Azeem, M.U., (2017). Self-efficacy to spur job performance: roles of job related anxiety and perceived workplace incivility. Management Decision, 56(4), 891-907.

Dreyfus, H. L. and Dreyfus, S. E. (1986) Mind over Machine: The Power of Human Intuition and Expertise in the Era of the Computer, New York, Free Press.

Flick, U., (2014). An introduction to qualitative research. SAGE publications.

Fook, J., Ryan, M. and Hawkins, L. (2000) Professional Expertise: Practice, Theory and Education for Working in Uncertainty. London, Whiting \& Birch.

Jack, G., Donnellan, H. (2010). Recognising the person within the developing professional: tracking the early carreers of newly qualified child care social workers in three local authorities in England. Social Work Education. 29(3), 305-318.

Janssen, M., van den Tillaart, B., van der Heijden, I., van Duijnhoven, A., van Son, N. (2002). Contact. Sint-Michielsgestel.

Janssen, M.J., Riksen-Walraven, J.M. \& van Dijk J.P.M. (2003). Towards a diagnostic Intervention model for fostering harmonious interactions between deafblind children and their educators. Journal of Visual Impairment and Blindness, 97, (4) 197-214.

Leman, P., Bremner, A., Parke, R.D., Gauvain, M. (2012). Developmental Psychology. McGraw Hill Education, Berkshire.

Liddell, S.K. (2003) Grammar, gesture and meaning in American Sign Language. Cambridge University Press.

Moriarty, J., Manthorpe, J., Stevens, M., Hussein, S. (2011). Making the transition: comparing research on newly qualified social workers with other professions. British Journal of Social Work. 41, 1340-1356.

Orpen, C., (1999). The impact of self-efficacy on the effectiveness of employee training. Journal of Workplace Learning: Employee Counselling Today. 11(4), 119-122.

Pithouse, A. and Scourfield, J. (2002). Ready for practice? The DipSW in Wales: Views from the workplace on social work training. Journal of Social Work, 2(1), 7-27.

Robson, C. (2011). Real World Research. WILEY Publications.

Rødbroe, I., Janssen, H.J.M. (2006). Communication and Congenital Deafblindness I: Congenital Deafblindness and the core principles of intervention. VCDBF/Viataal, St. Michielsgestel. 
Scholes, J., Petty, N.J., Mcintosh, T., Green, A., Flegg, M. (2017). Managing support for newly qualified practitioners: lessons learnt from one health care region in the UK. Journal of Nursing Management. 25, 102-109.

Souriau, J. (2015). Blended spaces and deixis in communicative activities involving persons with congenital deafblindness. Journal of Deafblind Studies on Communication. 1, 5-22.

Souriau, J., Rødbroe, I., Janssen, H.J.M. (2008). Communication and Congenital Deafblindness III: Meaning Making. VCDBF/Viataal, St. Michielsgestel.

Souriau, J., Rødbroe, I., Janssen, H.J.M., (2008). Emil and the slide [DVD]. SintMichielsgestel, Nederland: Viataal.

Souriau, J., Rødbroe, I., Janssen, H.J.M., (2008). Ingerid and the crab [DVD]. SintMichielsgestel, Nederland: Viataal.

Whallett, A. (2017). Supporting new (and not so new) health professionals. The Clinical Teacher. 14, 224-225.

Kim E. Tosolini, Mastertrack Pedagogical Sciences, Communication and Deafblindness, University of Groningen, The Netherlands; e-mail: <k.e.tosolini@rug.nl>. 